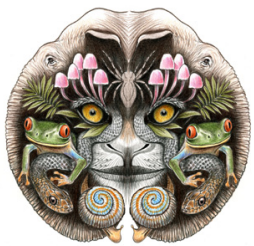

ISSN

Online 0974-7907

Print 0974-7893

OPEN ACCESS

\title{
NOTES ON THE DIET AND HABITAT SELECTION OF THE SRI LANKAN LEOPARd PANTHERA PARDUS KOTIYA (MAMMALIA: FELIDAE) IN THE CENTRAL HIGHLANDS OF SRI LANKA
}

\author{
Andrew M. Kittle ${ }^{1}$, Anjali C. Watson ${ }^{2}$, P.H.S. Chanaka Kumara ${ }^{3}$, \\ S.D. Kashmi C. Sandanayake ${ }^{4}$, H.K. Nimalka Sanjeewani ${ }^{5}$ \& T. Saminda P. Fernando ${ }^{6}$ \\ 1,2,3,4,5,6 The Leopard Project, Wilderness \& Wildlife Conservation Trust, 130 Reid Avenue, Colombo 4, Sri Lanka \\ ${ }^{1}$ Department of Integrative Biology, University of Guelph, Guelph, Ontario, Canada \\ 3,4,5 Department of Natural Resources, Faculty of Applied Sciences, Sabaragamuwa University of Sri Lanka, \\ Belihul Oya, Sri Lanka \\ ${ }^{6}$ Department of Zoology, University of Colombo, Colombo, Sri Lanka \\ ${ }^{1}$ akittle@uoguelph.ca (corresponding author), ${ }^{2}$ aalanka@sltnet.lk, ${ }^{3}$ greatlife.Ik@gmail.com, \\ ${ }^{4}$ kcsandanayake@gmail.com, ${ }^{5}$ nimalka.sanjeewani@gmail.com, ${ }^{6}$ samijaela@yahoo.com
}

\begin{abstract}
The endangered Sri Lankan Leopard Panthera pardus kotiya occupies the island's highly fragmented central hills where data on its feeding ecology and habitat use is largely absent. This study's objective was to investigate diet and resource selection of leopards here with a focus on the extent of potential interactions with humans in this heavily populated, largely unprotected landscape. Fecal sample analysis was undertaken to investigate diet and sign index counts and selectivity index analysis to determine habitat and landscape features important to fine scale leopard utilization. Results indicated that leopards in the central hills hunt a wide range of prey (at least 10 genera), including larger species where available (e.g., Sambar Rusa unicolor) and smaller, more specialized prey (e.g., Porcupine Hystrix indica) where necessary. No domestic species were recorded in scat analysis $(\mathrm{N}=35)$ despite the availability of dogs Canis familiaris, suggesting such predation may be atypical in Sri Lanka. Leopards use a range of landscapes within the region including established and regenerating forests, plantation lands (e.g., pine, eucalyptus, tea), and areas in close proximity to human settlement. At a fine scale, areas of dense undergrowth including tall grasslands were preferred to more open forest, as well as to Pine Pinus caribaea monocultures. Avoidance of humans may be influencing these patterns. This study has important implications as researchers and managers necessarily expand beyond focusing on protected areas toward integrated, landscape-level conservation strategies.
\end{abstract}

Keywords: Anthropogenic disturbance, diet, habitat use, Panthera pardus kotiya, unprotected areas.

DOI: http://dx.doi.org/10.11609/JoTT.03731.6214-21

Editor: Shomita Mukherjee, SACON, Coimbatore, India.

Date of publication: 26 August 2014 (online \& print)

Manuscript details: Ms \# 03731 | Received 02 August 2013 | Final received 18 April 2014 | Finally accepted 11 August 2014

Citation: Kittle, A.M., A.C. Watson, P.H.S.C. Kumara, S.D.K.C. Sandanayake, H.K.N. Sanjeewani \& T.S.P. Fernando (2014). Notes on the diet and habitat selection of the Sri Lankan Leopard Panthera pardus kotiya (Mammalia: Felidae) in the central highlands of Sri Lanka. Journal of Threatened Taxa 6(9): 6214-6221; http:// dx.doi.org/10.11609/JoTT.03731.6214-21

Copyright: (c) Kittle et al. 2014. Creative Commons Attribution 4.0 International License. JoTT allows unrestricted use of this article in any medium, reproduction and distribution by providing adequate credit to the authors and the source of publication.

Funding: PTES (People's Trust for Endangered Species) UK grant and contributions from CERZA Conservation, France and Le parc des Félins, France.

Competing Interest: The authors declare no competing interests.

Author Contribution: AMK supervised data collection, analyzed data and wrote the paper; ACW supervised data collection and wrote the paper; PHSCK collected data and conducted laboratory analysis; SDKCS collected and analyzed data; HKNS collected data and coordinated map design; TSPF conducted laboratory analysis.

Acknowledgements: We would like to thank the Kandy Municipal Council for permits and Hemantha Ekanayake and staff for support at Dunumadallawa forest reserve; Rohan Pethiyagoda for encouraging and supporting our work in the Agrapatana Arboretum; and Sri Lankan Department of Wildlife Conservation and Forestry Department for continued support and permits. Laboratory space was generously provided by Colombo University in liaison with Dr. Devaka Weerakoon.
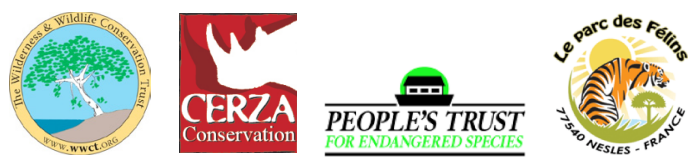


\section{INTRODUCTION}

The Sri Lankan Leopard Panthera pardus kotiya is an Endangered (Kittle \& Watson 2008) endemic subspecies and the island's apex predator (Miththapala et al. 1996; Uphyrkina et al. 2001). It has evolved without intra-guild competition at least since Sri Lanka split off from the Indian subcontinent $~ 5,000-10,000 \mathrm{ybp}$ (Deraniyagala 1992; Yokoyama et al. 2000), a unique scenario which may mean that this top carnivore is of keystone importance to the system (Paine 1966).

Data on the island-wide distribution and relative abundance of leopards is becoming increasingly refined (Kittle \& Watson 2008; Kittle et al. 2012) and it is now acknowledged that these versatile predators occupy unprotected as well as protected areas (Watson \& Kittle 2004). Between these extremes are semi-protected areas, small forest reserves and sanctuaries demarcated on paper but not actively patrolled and routinely utilized by people. Wildlife populations in unprotected and semi-protected areas are particularly susceptible to heightened levels of human-wildlife conflict.

Sri Lanka is a small $\left(65,610 \mathrm{~km}^{2}\right)$ mostly rural $(74-78$ \%) nation with substantial spatial overlap between humans and wildlife (Dept of Census and Statistics 2012). In the central hills, high human population density (301-450 / km², Dept of Census and Statistics 2012), heterogeneous land cover and a lack of protected areas makes understanding leopard diet and resource selection vital. Minimal diet analysis has been conducted here (Ranawana et al. 1998) and leopard diet outside protected areas remains unknown. Furthermore, how leopards use this heavily fragmented habitat mosaic has not been investigated. This data deficiency has been recognized as a barrier to designing conservation and management action plans to ensure the leopard's continued survival in the wild (Samarakoon 1999). A minimum of 66 leopards were killed island-wide from 2002-2012, mostly caught in snares set for other species (Kittle \& Watson, unpublished data). True mortality figures are unknown but if leopards are preying on domestic species outside protected areas, humanleopard conflict is likely to increase.

Our research objective was to investigate leopard diet and habitat use at two semi- to un-protected study sites in the central hills where leopards have been previously documented (Kittle et al. 2012).

\section{Study Areas}

The central highlands occupy a $\sim 2400 \mathrm{~km}^{2}$ section of Sri Lanka's south-central interior (Fig. 1), encompassing

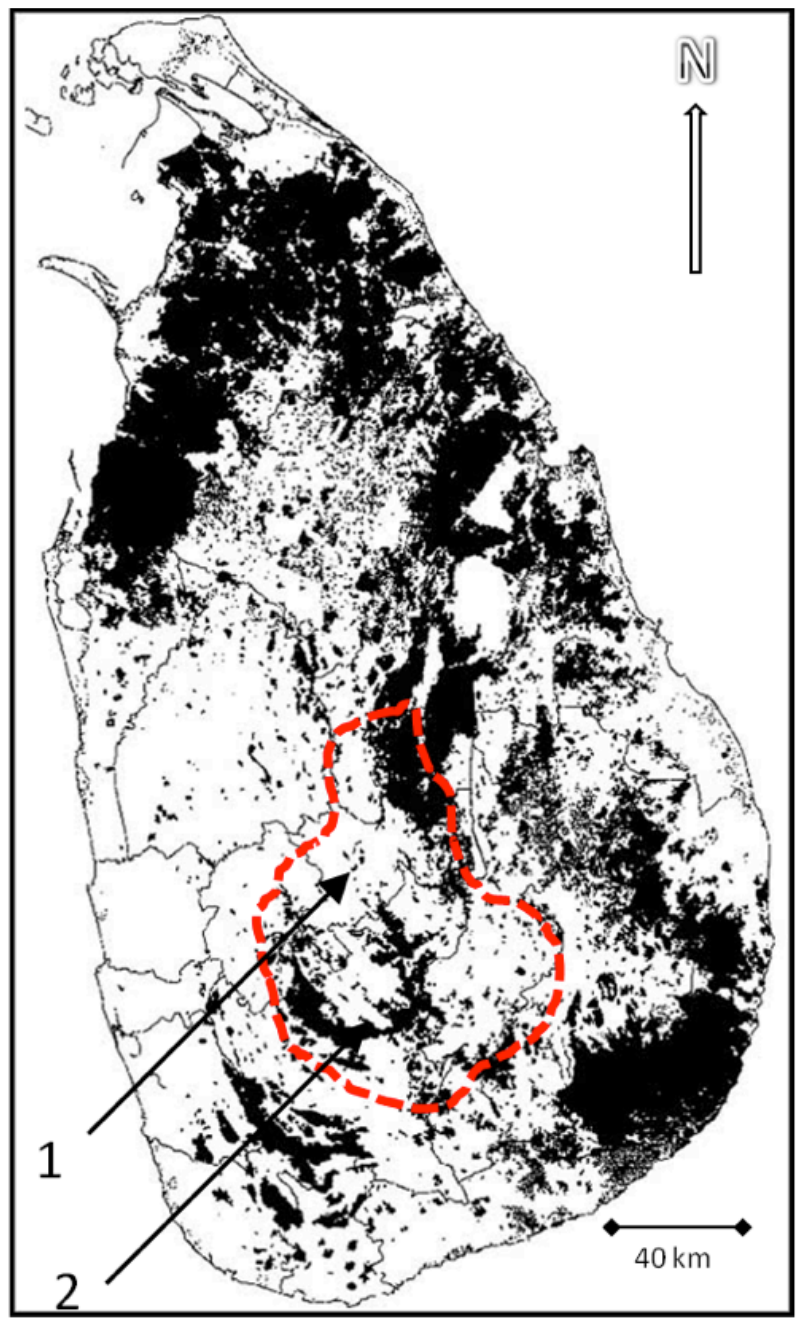

Figure 1. Map of Sri Lanka showing remaining forest cover (black). Approximate extent of central highlands is outlined in dashed red with hill country study sites indicated by arrows. 1 = Dunumadalawa forest reserve, 2 = Agrapatana study area.

a vast expanse of often-rugged terrain, which varies greatly in elevation, topography and climate.

The Dunumadalawa Forest Reserve is a secondary growth mid-country wet zone forest situated at the northern end of Sri Lanka's Central massif (Figs. 1, 2a). This was an active estate until the early 1900s when it was released from plantation use (tea, coffee and cocoa) and allowed to naturally re-generate, with some active reforestation of native plant species since 2000 . It now protects the watershed of two reservoirs providing water for Kandy, a town of 100000 within the limits of which the reserve is located. Dunumadalawa is characterized by high canopy mixed forest which includes Albizia sp. and jak Artocarpus heterophyllus remaining from the estate days. Large-leaf Mahogany Sweitinia macrophylla, Ceylon Almond Canarium zeylanicum and various 


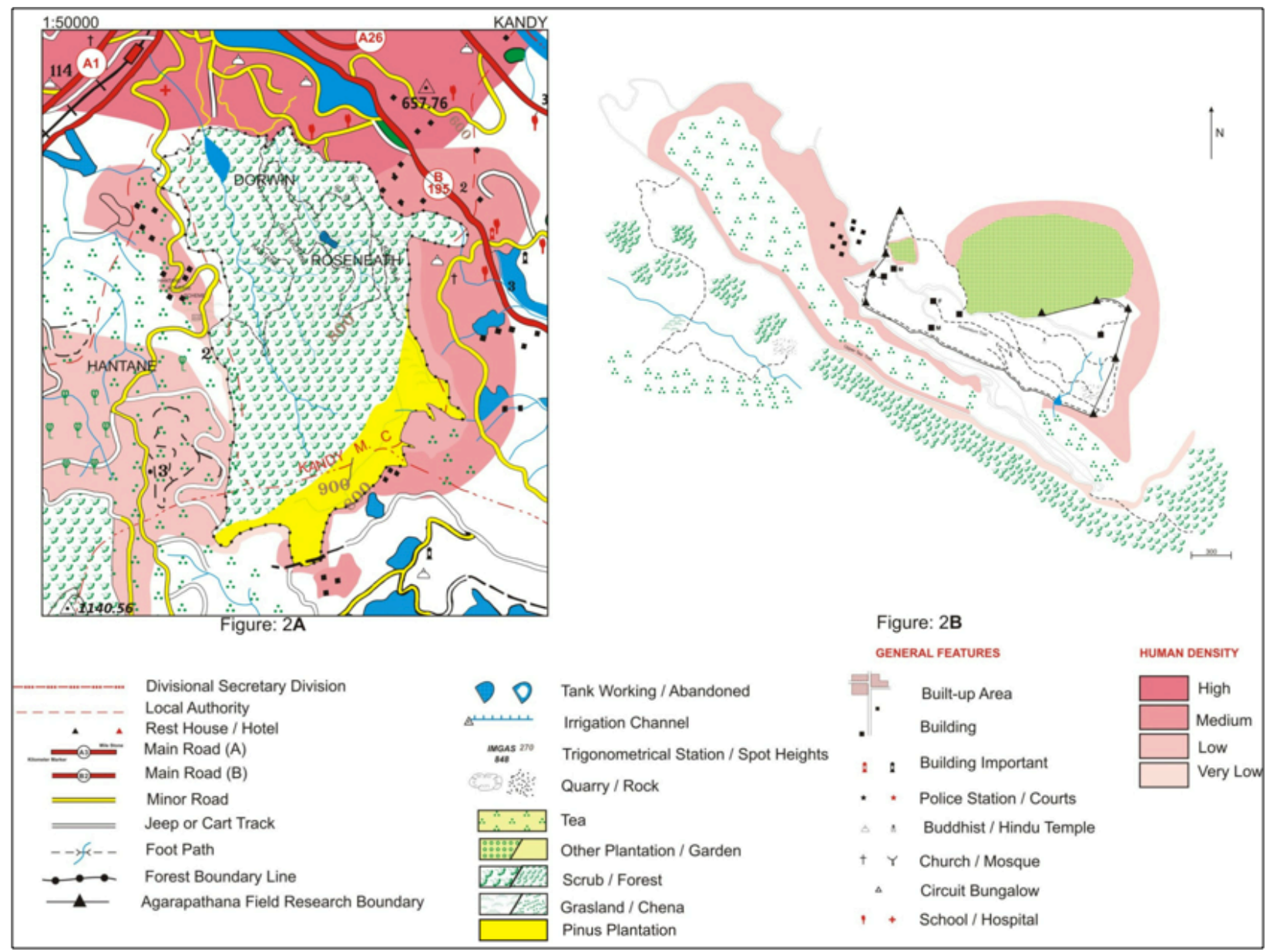

Figure 2 (a-b). Map of (a) Dunumadalawa forest reserve and (b) Agrapatana study area in context of surrounding landscape. Areas of high, medium and low human population pressure are indicated. Trails/roads used for prey index and habitat selection inside Dunumadalawa are shown but details of those interior trails/roads are not represented.

Ficus species are also conspicuous. The understory is dominated by unattended tea, coffee and cocoa plants grown wild in sections and the ironwood tree Mesua ferrea in others. Patches of grassland, composed mostly of Imperata cylindrica are scattered throughout the reserve. This grass can grow up to $3 \mathrm{~m}$ tall and form dense monocultures. The abundant jak appears to provide an important continuous food source for potential leopard prey species including Toque Macaques Macaca sinica aurifrons, Barking Deer Muntiakus muntjak, Wild Boar Sus scrofa and Porcupines Hystrix indica. The reserve includes a small (<40ha) Caribbean Pine Pinus caribaea plantation at its highest point in the southeast. Anthropogenic disturbance is acute in the surrounding area which is characterized by a mosaic of land-use types including sub-montane forest, tea estates, pine and eucalyptus plantations, open scrub, home gardens and villages. The reserve falls under the purview of the Kandy Municipal Council and is extensively utilized by a number of surrounding villages for firewood and fruit collection.

The Agrapatana Arboreatum is in the heart of the tea industry's vast plantation lands near the southern extent of the central hills (Figs. 1, 2b; Image 1). A regenerating forest, this was part of a much larger tea estate until the 1990s. It adjoins the Agra-Bopats Forest Reserve, a thickly vegetated 9,800 ha sub-montane, montane and cloud forest bordered by tea estates on three sides and connected to Horton Plains National Park (3160ha) to the southeast. Sambar Deer Rusa unicolor, Wild Boar Sus Scrofa, Toque Macaque Macaca sinica, Purple-faced Langur Trachypithecus vetulus and Porcupine all reside within this forest reserve. The two study areas differ in a number of important aspects (Table 1). 


\section{METHODS}

Diet: Leopard scat was collected opportunistically and during regular sign index surveys (Rabinowitz 1997) conducted between 2003 and 2009. These were air dried and stored in re-sealable plastic bags. To differentiate leopard from Fishing Cat Prionailurus viverrinus scat only samples with bolus width $>2.5 \mathrm{~cm}$ were retained (Henschel \& Ray 2003). Samples were washed and sieved to eliminate unwanted particles, and bones, quills, nails and hooves were manually separated and identified. Remaining hairs were mixed and oven dried at $60^{\circ} \mathrm{C}$ for $24 \mathrm{hr}$. Dried samples were placed in a shallow dish, a point grid overlaid and 50 hairs randomly sampled (Ciucci et al. 2004). Microscopic analysis followed Amerasinghe et al. (1990).

Habitat selection: We investigated fine scale leopard habitat selection at Dunumadallawa by comparing habitat variables at used and available locations (Table 2). Used locations were defined by the presence of leopard spoor (scat, pugmarks, scrapes) on reserve trails detected during regular sign index surveys between 2003 and 2009. Available locations were determined from a systematic random sample conducted in November 2009 , with points taken every $100 \mathrm{~m}$ along the same reserve trails. Four trails $(1300-2000 \mathrm{~m})$ that traverse the forest reserve were utilized for the use/availability analysis.

We used Jacob's selectivity index to determine
Table 1. Comparison of study areas in central hills, Sri Lanka.

\begin{tabular}{|l|l|l|}
\hline & $\begin{array}{l}\text { Dunumadallawa } \\
\text { Forest }\end{array}$ & $\begin{array}{l}\text { Agrapatana } \\
\text { Arboreatum }\end{array}$ \\
\hline Coordinates (Lat/Long) & $7^{0} 16^{\prime} \mathrm{N} \& 80^{\circ} 38^{\prime} \mathrm{E}$ & $6^{0} 50^{\prime} \mathrm{N} \& 80^{\circ} 40^{\prime} \mathrm{E}$ \\
\hline Size (ha) & 480 & 50 \\
\hline Elevation (masl) & $550-980$ & $1500-2000$ \\
\hline Average temperature $\left({ }^{\circ} \mathrm{C}\right)$ & $20-25$ & $<20$ \\
\hline $\begin{array}{l}\text { Annual precipitation } \\
\text { (mm) }\end{array}$ & $1500-3000$ & $1500-3000$ \\
\hline Forest classification & $\begin{array}{l}\text { mid-elevation wet } \\
\text { zone }\end{array}$ & sub-montane \\
\hline $\begin{array}{l}\text { Released from plantation } \\
\text { status }\end{array}$ & early 1900s & 1990 s \\
\hline Current protection status & $\begin{array}{l}\text { Semi (Kandy } \\
\text { Municipal Council) }\end{array}$ & None (Private) \\
\hline Surrounding land use & $\begin{array}{l}\text { tea estate/urban/ } \\
\text { village/home } \\
\text { garden/scrub }\end{array}$ & $\begin{array}{l}\text { tea estate/ } \\
\text { reserve }\end{array}$ \\
\hline Human disturbance level & High & Low \\
\hline Number of scats & 13 & 22 \\
\hline
\end{tabular}

habitat selection where data was categorical (Fig. 3):

$$
D=(r-p) /(r+p-2 r p)
$$

where $r$ is the proportion of used locations of a given habitat/landscape class and $p$ is the proportional availability of that habitat/landscape class (Jacobs 1974). Values of $D$ range from -1 indicating maximum avoidance to 1 indicating maximum selection, with 0 value indicating use in proportion to availability (Jacobs

Table 2. Description of variables investigated for Leopard habitat selectivity analysis.

\begin{tabular}{|c|c|c|}
\hline Variable name & Data type & Description \\
\hline Habitat type & Categorical & $\begin{array}{l}5 \text { categories - human settlement (areas beside reserve office, bungalow or border Village), } \\
\text { grassland (tall, } 30 \mathrm{~cm}-2 \mathrm{~m} \text {, Imperata cylindrica), pine plantation (Pinus caribaea), forest (typical } \\
\text { mid-country wet zone type), and mixed (areas of more than one of the former classes, e.g., } \\
\text { forest/grassland boundary) }\end{array}$ \\
\hline Trail type & Categorical & $\begin{array}{l}3 \text { categories - dirt roads (open, flat and accessible (but rarely used) to all vehicle types); jeep } \\
\text { tracks (partially overgrown, uneven, only } 4 \times 4 \text { vehicles); walking trails (narrow footpaths) }\end{array}$ \\
\hline Understory density & Categorical, ordinal & $\begin{array}{l}\text { Determined qualitatively and categorized as Dense ( } 80-100 \% \text { coverage), Moderate (50-80 \%), } \\
\text { Light }(<50 \%) \text { and None (no understory). }\end{array}$ \\
\hline Degree of human disturbance & Categorical, ordinal & $\begin{array}{l}\text { Determined qualitatively and categorized as High (frequently used by reserve staff and/or } \\
\text { villagers), Moderate (sometimes used) and Light (almost never used). No areas were unused. }\end{array}$ \\
\hline Slope & Continuous & Visually estimated for immediate location. Range from 0 (flat) to $60^{\circ}$. \\
\hline Elevation & Continuous & Determined at each location from previously calibrated handheld GPS (Garmin e-trex summit). \\
\hline Tree density & Continuous & The distance to 5 nearest trees measured and averaged. \\
\hline Tree size & Continuous & The DBH of 5 nearest trees measured and averaged. \\
\hline Canopy cover & Continuous, grouped & Determined using simple densiometer. Grouped into 5 categories - 0, 1-25, 26-50, 51-75, 76-100. \\
\hline Distance to permanent water & Continuous, grouped & $\begin{array}{l}\text { Determined from each location using previously created GPS map. Grouped into } 3 \text { categories - } \\
0-100 m, 100-500 m,>500 m\end{array}$ \\
\hline Distance to human settlement & Continuous, grouped & $\begin{array}{l}\text { Determined from each location using previously created GPS map. Grouped into } 3 \text { categories - } \\
0-100 m, 100-500 m,>500 m\end{array}$ \\
\hline
\end{tabular}






Figure 3a. Bar plots representing Jacob's selectivity index values for leopards in Dunumadalawa forest reserve in the central hills, Sri Lanka. Habitat and landscape measures are based on comparison of locations used by leopards as detected by sign or observation ( $\mathrm{N}=39$ ) and a systematic random sample of available points $(\mathrm{N}=68)$. Values range from -1 which indicates maximum avoidance to 1 which indicates maximum selection. No selection is indicated by a value of 0 .

1974). This selectivity index minimizes bias from small sample sizes (e.g., rare food items or habitat proportions $<10 \%$; Hayward \& Kerley 2005). Continuous data was not normally distributed but had equal variance (Levene's test $\mathrm{P}>0.05$ ) so Mann-Whitney Test was used for analysis (Zar 1999).

\section{RESULTS}

Diet: Of the 42 scat samples collected, 35 produced results: 13 from Hantane and 22 from Agrapatana (Table 3). Porcupine was the most frequently represented species found in scat at Dunumadalawa, followed by Barking Deer, whereas Sambar was the most common species in leopard scat in Agrapatana (Table 3). Domestic species were not represented in samples from either location (Table 3).

Habitat selection: Thirty-nine used locations were compared to 68 available locations within Dunumadalawa. Leopards utilized the entire $5 \mathrm{~km}^{2}$ study area but showed selection for grasslands (Jacob's Index $=0.9963$ ) and avoidance of the Pinus plantation (Jacob's

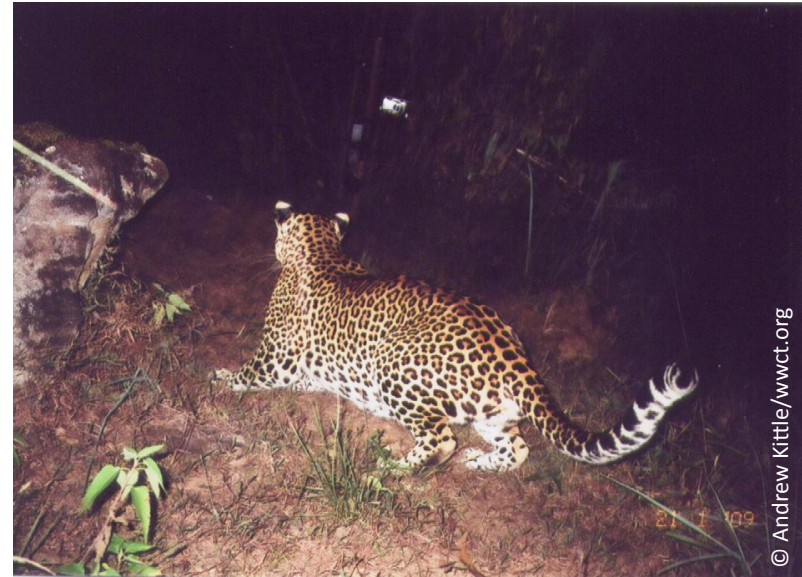

Image 1. Young adult female leopard camera trapped in the Agrapatana arboretum. This photo was taken on a walking trail within a regenerating tea estate.

Index $=-0.9867$, Fig. 2a). Areas with dense understory (Jacob's Index $=0.8158$ ) and no canopy cover (Jacob's Index $=0.7143$ ) were selected, whereas areas with sparse canopy cover (0-25\%) were avoided (Jacob's 
Table 3. Scat analysis results from Dunumadalawa and Agrapatana study sites. Results are \% of total scats containing each prey species. Herpestes could not be discerned to species level.

\begin{tabular}{|l|c|c|}
\hline Prey species & $\begin{array}{c}\text { Dunumadalawa } \\
\text { (N = 13) }\end{array}$ & $\begin{array}{c}\text { Agrapatana } \\
\text { (N = 22) }\end{array}$ \\
\hline Cervus unicolor Sambar & 0 & 59.1 \\
\hline Funambulus palmarum Palm Squirrel & 7.7 & 0 \\
\hline Herpestes sp. Mongoose & 0 & 4.5 \\
\hline Hystrix indica Porcupine & 61.5 & 4.5 \\
\hline Lepus nigricollis Black-naped Hare & 7.7 & 13.6 \\
\hline $\begin{array}{l}\text { Macaca sinica aurifrons Toque } \\
\text { Macaque }\end{array}$ & 7.7 & 4.5 \\
\hline Moschiola meminna Mouse Deer & 7.7 & 4.5 \\
\hline Muntiacus muntjak Barking Deer & 30.8 & 0 \\
\hline Sus scrofa Wild Boar & 7.7 & 0 \\
\hline $\begin{array}{l}\text { Trachypithecus vetulus Purple-faced } \\
\text { Langur }\end{array}$ & 0 & 13.6 \\
\hline
\end{tabular}

Index $=-0.6277)$. Areas far from permanent water (Jacob's Index $=0.5790$ ) were preferred to areas close to permanent water (Jacob's Index $=-0.5014$, Fig. 2b).

Neither slope $\left(Z_{w}=0.537, p=0.5907\right)$ or elevation $\left(Z_{w}=1.405, p=0.1611\right)$ were significant factors influencing fine scale habitat use, however leopards did prefer areas with lower tree density $\left(Z_{w}=-2.443, p=.0147\right)$ and larger trees $\left(Z_{w}=-1.919, p=0.0554\right)$.

\section{DISCUSSION}

Diet: Sample size is too small to definitively characterize leopard diet in these areas (Mukherjee et al. 1994; Trites \& Joy 2005), but given the complete dearth of dietary data from un-protected areas in the central highlands, even this preliminary information is valuable. The dietary breadth observed is wide, including 10 genera ranging in size from 112g (Palm Squirrel; Phillips 1980 ) to $130 \mathrm{~kg}$ (Sambar hind; Phillips 1984). This catholic diet is consistent with leopard feeding ecology throughout its range reflecting opportunistic predation and the leopard's adaptive ability to broaden its diet beyond the preferred range of medium-sized ungulates, 23-56 kg (Stander et al. 1997; Hayward et al. 2006).

The Indian Porcupine was represented most frequently in scat $(61.5 \%)$ in the small, isolated forest reserve despite it being absent from Hayward's (2006) exhaustive analysis of leopard prey preferences (111 prey species). Porcupines are potentially dangerous prey, but the prey suite available to leopards in Dunumadalawa is relatively limited (Sanjeewani 2010), so the likelihood of risking injury to secure adequate resources is increased
(Brown \& Kotler 2007). Alternately, leopards here may have adapted to hunting porcupines with minimum risk or a single leopard may be responsible for the majority of the scat samples collected here, although three individuals have been observed in the reserve (Kittle et al. 2012). Prey specialization by individuals within a population is not uncommon across taxa (Araújo et al. 2011) including among apex terrestrial carnivores (Ross et al. 1997; Elbroch \& Wittmer 2013). Establishing whether observations are the reflection of a populationlevel adaptation to the suite of resources available or a case of individual specialization requires additional sampling. The implications of either can be profound (Bolnick et al. 2003).

In Agrapatana Sambar was most frequently represented in scat samples (59.1\%), consistent with probable prey availability, given that the study area is contiguous with Horton Plains National Park (HPNP) where sambar density is estimated to be $66.5 / \mathrm{km}^{2}$ (Rajapakse 2003). Previous scat analysis from HPNP found sambar in $75.8 \%$ of samples $(\mathrm{N}=22)$ (Ranawana et al. 1998). That fewer samples contained Sambar here than in HPNP, and more contained Black-naped Hare and Purple-faced Langurs (Table 3; 13.6\% compared to $6.8 \%$ and $3.4 \%$ in HPNP, Ranawana et al. 1998) hints at variation in prey availability between the core of a protected area such as HPNP and an adjoining yet peripheral area such as Agrapatana. More samples are needed to validate this hypothesis.

Scat samples included no domestic species at either site despite dogs being common at both. This suggests low human-leopard conflict in these regions despite close proximity to human populations, but given the low sample size, interpretations must be made with caution. In Dunumadalawa dogs have been predated in the past, however, these incidents may be uncommon. Questionnaire surveys here show fishing cats responsible for some predation events blamed on leopards (Kittle \& Watson, unpublished data). That predation on domestic animals appears atypical is relevant from a management perspective since predators viewed as a menace tend to be increasingly persecuted (Cavalcanti et al. 2010).

Habitat selection: Leopards in the Dunumadalawa Forest Reserve may be selecting fine scale habitats offering improved hunting efficiency. Leopards and lions select areas of high prey vulnerability not high prey density at the fine scale (Hopcraft et al. 2005; Balme et al. 2007; Davidson et al. 2012). As ambush predators, leopards require at least $20 \mathrm{~cm}$ of cover for concealment (Bothma \& LeRiche 1984), so tall grasses $(>30 \mathrm{~cm})$ and thick vegetation are sufficient. However, 
in South Africa hunting leopards select intermediate cover, presumably because dense cover obscures their perception of prey (Balme et al. 2007). Alternatively then, where anthropogenic disturbance is high such as in isolated forests within densely populated urban areas, dense undergrowth and long grass might provide leopards concealment from people, a potential risk in this environment. Avoidance of permanent water may also indicate avoidance of people as the reserve's two large permanent water sources are regularly monitored by Water Department personnel. However, leopards did not avoid other high human-use areas (e.g., border villages). The reserve is replete with seasonal streams and pools which allow leopards to effectively exploit areas far from permanent sources.

In summary, this research provides valuable insight into the diet and habitat selection of an endangered apex predator, in an area of its range with little existing information and where it is afforded limited protection. Avoidance of humans in these heavily disturbed landscapes may be an important consideration for leopards when making space-use decisions, as it is in parts of their African range where bush meat is an important commodity and humans and leopards engage in a form of exploitative competition (Henschel et al. 2011). Camera trap images revealed leopards and humans engaged in temporal niche partitioning in both sites, with humans detected in the day and leopards at night at the same location (Kittle et al. 2012). Temporal niche partitioning is a mechanism used to explain carnivore co-existence in Africa (Hayward \& Slotow 2009) and might similarly be important in South Asia where top carnivores necessarily share space with humans (Athreya et al. 2013).

As human populations continue to increase and protected areas become more and more isolated (DeFries et al. 2005), the effective conservation of biodiversity becomes increasingly reliant on processes outside protected areas (Hansen \& DeFries 2007). These areas tend towards habitat mosaics with forested areas heavily fragmented and surrounded by a patchwork of alternate land use types. Large, wide-ranging species such as top carnivores nevertheless often persist (LyraJorge et al. 2008) and can be adept at exploiting semi and unprotected areas even where human density is high (Athreya at al. 2013). We are increasingly recognizing the value of these sub-optimal, shared habitats in terms of connectivity and as supplements to remaining forest fragments (Caryl et al. 2012), as well as appreciating the important role played by predators in maintaining biodiversity within such fragments (Terborgh et al.
2001). As such, the need to increase our understanding of how apex predators utilize these landscape mosaics is of paramount importance.

\section{REFERENCES}

Amerasinghe, F.P., U.B. Ekanayake \& R.D.A. Burge (1990). Food habits of the leopard (Pantherapardusfusca) in Sri Lanka. Ceylon Journal of Science 21: 17-24.

Araújo, M.S., D.L. Bolnick \& C.A. Layman (2011). The ecological causes of individual specialization. Ecology Letters 14: 948-958; http:// dx.doi.org/10.1111/j.1461-0248.2011.01662.x

Athreya, V., M. Odden, J.D.C. Linnell, J. Krishaswamy \& U. Karanth (2013). Big cats in our backyards: Persistence of large carnivores in a human dominated landscape in India. PlosOne 8(3): e57872; http:// dx.doi.org/10.1371/journal.pone.0057872

Balme, G., L. Hunter \& R. Slotow (2007). Feeding habitat selection by hunting leopards Panthera pardus in a woodland savanna: prey catchability versus abundance. Animal Behavior 74: 589-596; http:// dx.doi.org/10.1016/j.anbehav.2006.12.014

Bolnick, D.I., R. Svanbäck, J.A. Fordyce, L.H. Yang, J.M. Davis, C.D. Hulsey \& M.L. Forister (2003). The ecology of individuals: Incidence and implications of individual specialization. American Naturalist 161(1): 1-28; http://dx.doi.org/10.1086/343878

Bothma, J.D.P. \& E.A.N. Le Riche (1984). Aspects of the ecology and the behavior of the Leopard (Panthera pardus) in the Kalahari desert. Koedoe, Supplement 27: 259-279.

Brown, J.S. \& B.P. Kotler (2007). Foraging and the ecology of fear, pp. 437-480. In: Stephens, D.W., J.S. Brown \& R.C. Ydenberg (eds.). Foraging behavior and ecology. University of Chicago Press, Chicago, xv+608pp.

Caryl, F.M., C.P. Quine \& K.J. Park (2012). Martens in the matrix: the importance of non forested habitats for forest carnivores in fragmented landscapes. Journal of Mammalogy 93(2): 464-474; http://dx.doi.org/10.1644/11-MAMM-A-149.1

Cavalcanti, S.M.C., S. Marchini, A. Zimmermann, E.M. Gese \& D.W. Macdonald (2010). Jaguars, livestock, and people in Brazil: realities and perceptions behind the conflict, pp. 383-402. In: Macdonald, D.W. \& A.J. Loveridge (eds.). Biology and Conservation of Wild Felids. Oxford University Press, Oxford, xix+762pp.

Ciucci, P., E. Tosoni \& L. Boitani (2004). Assessment of the point-frame method to quantify Wolf Canis lupus diet by scat analysis. Wildlife Biology 10(2): 149-153.

Davidson, Z., M. Valiex, A.J. Loveridge, J.E. Hunt, P.J. Johnson, H. Madzikanda \& D.W. MacDonald (2012). Environmental determinants of habitat and kill site selection in a large carnivore: scale matters. Journal of Mammalogy 93(3): 677-685; http://dx.doi. org/10.1644/10-MAMM-A-424.1

DeFries, R.A. Hansen, A.C. Newton \& M.C. Hansen (2005). Increasing isolation of protected areas in tropical forests over the past twenty years. Ecological Applications 15:19-26; http://dx.doi. org/10.1890/03-5258

Department of Census and Statistics (2012).Population Atlas of Sri Lanka. Ministry of Finance and Planning, Government of Sri Lanka, Colombo, Sri Lanka, 15pp.

Deraniyagala, S.U. (1992). The prehistory of Sri Lanka: an ecological perspective. Volume 8, Part 2, Archaeological Department, Colombo, Sri Lanka, 430pp.

Elbroch, M.L. \& H.U. Wittmer (2013). The effects of puma prey selection and specialization on less abundant prey in Patagonia. Journal of Mammalogy 94(2): 259-268; http://dx.doi.org/10.1644/12MAMM-A-041.1

Hansen, A.J. \& R. DeFries (2007). Ecological mechanisms lining protected areas to surrounding lands. Ecological Applications 17: 974-988; http://dx.doi.org/10.1890/05-1098

Hayward, M.W. \& G.I.H. Kerley (2005). Prey preferences of the Lion 
(Panthera leo). Journal of Zoology (London) 267: 309-322; http:// dx.doi.org/10.1017/S0952836905007508

Hayward, M.W., P. Henschel, J. O’Brien, M. Hofmeyr, G. Balme \& G.I.H. Kerley (2006). Prey preferences of the Leopard (Panthera pardus). Journal of Zoology (London) 270: 298-313.

Hayward, M.W. \& R. Slotow (2009). Temporal partitioning of activity in large African carnivores: tests of multiple hypotheses. South African Journal of Wildlife Research 39(2): 109-125; http://dx.doi. org/10.3957/056.039.0207

Henschel, P., L.T.B. Hunter, L. Coad, K.A. Abernethy \& M. Mühlenberg (2011). Leopard prey choice in the Congo Basin rainforest suggests exploitative competition with human bushmeat hunters. Journal of Zoology (London) 285: 11-20.

Henschel, P. \& J. Ray (2003). Leopards in African Rainforests: Survey and Monitoring Techniques. Wildlife Conservation Society's Global Carnivore Program, New York, USA, 50pp.

Hopcraft, G.C., A.R.E. Sinclair \& C. Packer (2005). Planning for success: Serengeti lions seek prey accessibility rather than abundance. Journal of Animal Ecology 74: 559-566; http://dx.doi.org/10.1111/ j.1365-2656.2005.00955.x

Jacobs, J. (1974). Quantitative measurement of food selection a modification of the forage ratio and Ivlev's electivity index. Oecologia 14: 413-417; http://dx.doi.org/10.1007/BF00384581

Kittle, A.M. \& A.C. Watson (2008). Panthera pardus ssp. kotiya. In IUCN 2012. 2012 IUCN Red List of Threatened Species <www. iucnredlist.org>. [Accessed on 09 March 2013]

Kittle, A.M., A.C. Watson, P.H.C. Kumara \& H.K.N. Sanjeewani (2012). Notes on the status, distribution and abundance of the Sri Lankan Leopard in the central hills of Sri Lanka. CatNews 56: 28-31.

Lyra-Jorge, M.C., G. Ciocheti \& V.R. Pivello (2008). Carnivore mammals in a fragmented landscape in northeast of São Paulo State, Brazil. Biodiversity and Conservation 17: 1573-1580; http://dx.doi. org/10.1007/s10531-008-9366-8

Miththapala, S., J. Seidensticker \& S.J. O'Brien (1996). Phylogeographic subspecies recognition in leopards (Panthera pardus): molecular genetic variation. Conservation Biology 4: 1115-1132.

Mukherjee, S., S.P. Goyal \& R. Chellam (1994).Standardisation of scat analysistechniques for Leopard (Panthera pardus) in Gir National Park, Western India.Mammalia 58: 139-143; http://dx.doi. org/10.1515/mamm.1994.58.1.139

Paine, R.T. (1966). Food web complexity and species diversity. American Naturalist 100: 65-75; http://dx.doi.org/10.1086/282400

Phillips, W.W.A. (1980). Manual of the Mammals of Sri Lanka, Part II. Wildlife and Nature Protection Society of Sri Lanka, $2^{\text {nd }}$ Edition, Colombo, xi+151pp.

Phillips, W.W.A. (1984). Manual of the Mammals of Sri Lanka, Part III. Wildlife and Nature Protection Society of Sri Lanka, $2^{\text {nd }}$ Edition, Colombo, xiv+120pp.
Rabinowitz, A. (1997). Wildlife Field Research and Conservation Training Manual. Wildlife Conservation Society, New York, USA, 277pp.

Ranawana, K.B., C.N.B. Bambaradeniya, T.D. Bogahawatte \& F.P. Amerasinge (1998). A preliminary survey of the food habits of the Sri Lanka Leopard (Panthera pardus fusca) in three montane wet zone forests of Sri Lanka. Ceylon Journal of Science 25: 65-69.

Rajapakse, I.K. (2003). Ecology of Sambar Deer (Cervus unicolor unicolor - Kerr, 1792) in relation to habitat requirements and predator pressure by the Leopard (Panthera pardus kotiya - Meyer, 1974) at the Horton Plains National Park of Sri Lanka. PhD Thesis. Open University of Sri Lanka, Colombo, Sri Lanka, vii+125pp.

Ross, P.I., M. Jalkotzy \& M. Festa-Bianchet (1997). Cougar predation on bighorn sheep in southwestern Alberta during winter. Canadian Journal of Zoology 75: 771-775; http://dx.doi.org/10.1139/z97-098

Samarakoon, P.A.G.V. (1999). Conserving the leopard in Sri Lanka: the need for a management strategy. Loris 22: 14-16.

Sanjeewani, H.K.N. (2010). Determining the abundance of prey available to leopards in a mid-elevation wet zone forest reserve: A comparison of methods. BSc. Thesis. Department of Natural Resources, Faculty of Applied Sciences, Sabaragamuwa University of Sri Lanka, xiii+44pp.

Stander, P.E., P.J. Haden, II. Kaqece \& II. Ghau (1997). The ecology of asociality in Namibian leopards. Journal of Zoology (London) 242: 343-364; http://dx.doi.org/10.1111/j.1469-7998.1997.tb05806.x

Terborgh, J., L. Lopez, P.V. Nuñez, M. Rao, G. Shahabuddin, G. Orihuela, M. Riveros, R. Ascanio, G.H. Adler, T.D. Lambert \& L. Balbas (2001). Ecological meltdown in predator-free forest fragments. Science 294: 1923-1926; http://dx.doi.org/10.1126/science.1064397

Trites, A.W. \& R. Joy (2005). Dietary analysis from fecal samples: how many scats are enough? Journal of Mammalogy 86: 704-712; http://dx.doi.org/10.1644/1545-1542(2005)086\%5B0704:DAFFSH \%5D2.0.CO;2

Uphyrkina, O., W. Johnson, H. Quigly, D. Miquelle, L.L. Markar, M. Bush \& S.J. O'Brien (2001). Phylogenetics, genome diversity and origin of modern Leopard (Panthera pardus). Molecular Ecology 10: 2617-2633; http://dx.doi.org/10.1046/j.0962-1083.2001.01350.x

Watson, A.C. \& A.M. Kittle (2004). Distribution and status of the Sri Lankan leopard - a short report. Cat News 41: 12-15.

Yokoyama, Y., K. Lambeck, P. de Deckker, P. Johnson \& L.K. Fifield (2000). Timing of the last glacial maximum from observed sea-level minima. Nature 406: 713-716; http://dx.doi.org/10.1038/35021035

Zar, J.H. (1999). Biostatistical Analysis - $4^{\text {th }}$ Edition. Prentice Hall, New Jersey, USA, 944pp.

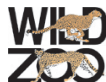

Author Details: ANDREW M. KITTLE is interested in ecological research which can be used to inform management and conservation policy. His main focus is carnivore behaviour and ecology, particularly spatial dynamics and resource selection, as well as how these relate to carnivore co-existence. ANJALI C. WATSON is interested in the ecology and conservation of the Sri Lankan Leopard as well as broader issues including wildlife and ecosystem health. P.H.S. CHANAKA KUMARA is interested in conservation biology. S.D. KASHMI C. SANDANAYAKE is undertaking her MPhil at the Post-Graduate Institute of Agriculture, University of Peradeniya where her primary interests are conservation biology and environmental science. H.K. NIMALKA SANJEEWANI is interested and engaged in the conservation of Sri Lanka's wildlife. T. SAMINDA P. FERNANDo has an interest in wildlife ecology and parasitology and is currently lecturing at the Open University of Sri Lanka. 